\title{
A Three-Dimensional FEA of Implants to Investigate Effects of Angle Implantation Cases in Implants Success
}

\author{
Zeinab Arsalanloo, Reza Telchi, and Kambiz Ghaemi Osgouie
}

\begin{abstract}
Implants should be placed, paralleled to adjacent tooth and be vertically aligned with axial forces. However, in many clinical instances, achieving this may be impossible due to deficiencies in alveolar bone. Clinically, many implant cases with different angulation over the lower posterior area have been found. Therefore, implants must be placed in angled positions, complicating restoration using straight abutments but on the other hand, angled abutments have been introduced to correct such cases. As regards, the major load in the anterior region is being entered by tongue to teeth and according to particular situation of lateral incisor tooth that has low space and also height limitation due to the existence of the sinus and nerves in maxilla and mandible, respectively, therefore this study is evaluated effects of angled installation of implants and use of the angled abutment. This paper was to discover desirable installation of implant and compare the relation between design angle abutment, angled installation of implants and load distribution at the implant bone interface with vertical abutment implantation and evaluate how could decrease stress and promote better stress distribution on surrounding bone of single-unit dental implants. Therefore, 26 solid models of the lateral incisor were built up and were transferred to mesh models in FEM to perform a stress analysis. In this study, static, dynamic and fatigue behaviors of the implant are investigated.
\end{abstract}

Index Terms - Dental implant, FEM, angle abutment, angled installation.

\section{INTRODUCTION}

Loss of teeth can lead to not only retardation of chewing ability, but also improper health status of dental bones and associative tissues. As one of the typical treatment strategies, dental implantation has gained significant popularity due to rapid development of more implantable biomaterials. Endosseous dental implants are currently used to retain and/or support prostheses for restoring completely or partially edentulous patients. Whether an implant is used following a period of undisturbed healing or immediately after placement, a number of clinical studies [1]-[3] have shown that the failure of osseointegrated implants is generally not related to mechanical failure of the load-bearing artificial structure (generally titanium based), whereas implant failure associated bone weakening or loss at the peri-implant region. According to the implantation history, in 1969, brånemark and colleagues reported a successful attempt of endosseous dental implant treatment.

Manuscript received February 13, 2014; revised April 25, 2014.

Zeinab Arsalanloo is with the Mechanical Engineering Dep. Vali-e-Asr University of Rafsanjan, Iran (e-mail: pendar.soyleyin@yahoo.com).

Reza Telchi and Kambiz Ghaemi Osgouie are with the School of Engineering and Science, Sharif University of Technology, International campus, Kish, Iran (e-mail: rezatelchi@gmail.com, osgouie@sharif.edu).
The long-term success of dental implant treatment relies on the proper stability of the implant within the host bone. This condition is achieved by several factors. One one of important of them is osseointegration, which is characterized as a directly functional and structural connection between ingrown bone tissue and implant surface [4]. Other factors can be categorized as surgical (primary stability and surgical technique), tissular (quality and quantity of bone, healing, remodeling), implantological (macrostructure, microstructure, and dimensions such as taper of implant, thread profile, material of implant, angle of implantation), and finally occlusal/mechanical (forces and prosthetic design) [5], [6]. In the last three decades and in the field of the prosthetic dentistry, features of dental implants and surgical procedures have been developed and enhanced aiming to ensure predictable results and to improve function and aesthetics in completely or partially edentulous patients [7].

In the regards of improve function of implant, in case of tooth loss in the anterior region is commonly the result of a traumatic injury, tooth decay or a congenital anomaly. Several options are available for the replacement of congenitally missing maxillary lateral incisor tooth. 1) these include removable dental prostheses, conventional fixed dental prostheses (fdps), resinbonded fdps, orthodontic repositioning of canines to close the edentulous space, and single-tooth implant deboning rates of $25-31 \%$ have been reported for these restorations [8], [9]. 2) in cases where the occlusion and esthetics of the canine in the lateral position are acceptable, closure of the lateral space by the mesially positioned canine, which may be the simplest alternative treatment option [8], [10]. 3) implants placed at positions off the vertical axis have been referred to as "tilted implants" or "off-axis fixtures." These may be placed to avoid various anatomical structures or to eliminate the need for bone grafting and nerve repositioning procedures. 4) dental implant is an appropriate treatment option for replacing missing maxillary lateral incisor tooth in adolescents when their dental and skeletal development is complete [11]-[13].

Ideally, implants should be placed parallel to each other and to adjacent teeth and be aligned vertically with axial forces. However, achieving this may not be possible owing to deficiencies in the ridge's anatomy. To compensate for ridge topography that is less than ideal, the clinician can follow one of several scenarios to enhance placement of implants: augue the ridge, change the intended location of an implant or insert an implant with an angled trajectory. Therefore, according to position of lateral incisor tooth, in the anterior maxilla/mandible, the placement of an implant in a prosthetically ideal position is often not possible because of the lack of sufficient bone, vertically or horizontally 
limitations [14]. In this case, because of esthetic or spatial needs, usually angulated implantation and/or angled abutments are often needed to placement of dental implants in the esthetic zone. Frequently implants must be placed in angled positions, complicating restoration using straight abutments. Angled abutments have been introduced to correct such cases [15]-[17]. The advent of angulated abutments has facilitated the parallelism of non-aligned implants thereby making the prosthesis fabrication easier. This is particularly useful in clinical situations where anatomic constraints and other reasons compel to surgically position implants at angles that are not favorable for prosthetic rehabilitation. Up to now, various studies were done to investigate the angulated implantation and angled abutment, but none of them have been about the lateral incisor tooth. In addition, the most studies are experimental. Some of the previous studies are as follows.

Eger et al. [18] concluded that implants placed at unfavorable angles may be restored with angled abutments without compromise of function or esthetics. Sethi et al. [19], [20] published two articles as following, 3,100 angle corrected restorations over 10 years, and concluded that good esthetic and functional results can be achieved. Maló et al. [21] used implants in the maxilla and mandible in a method similar to krekmanov, except that most of these implants were immediately restored. At one year, maló concluded that this treatment modality was highly successful. Rosén et al. [22] followed implants in the maxilla for 8 to 12 years that were tilted to avoid grafting procedures. They concluded that this was a successful alternative procedure to more resource-demanding techniques involving bone grafting. Calandriello et al. [23] showed similar findings in a 1-year follow-up study. Krennmair et al. [24] studied 62 patients with mandibular over dentures and analyzed the various angles of the implants for optimal restoration. They concluded that sagittal mandibular inclination should be attributed more importance than axial loading of implants. Aparicio et al. [25] followed fixed implant bridges supported by both axial and tilted implants for 21 to 87 months post-insertion and concluded that the use of tilted implants is an effective and safe alternative to the maxillary sinus floor augmentation procedure.

In this paper, we will investigate angulated implantation method and use of angled abutment in lateral incisor position by using the finite element method (fem). We hope to discover a desirable installation of implant and compare the relation between design angle abutment, angled installation of implants and load distribution at the implant bone interface with vertical abutment implantation and evaluate how could decrease stress and promote better stress distribution on surrounding bone of single-unit dental implants. Therefore, 34 solid models of the lateral incisor were built up and then were transferred to a mesh model in fem to perform a stress analysis. In this study, static, dynamic and fatigue behaviors of the implant are investigated.

\section{MEthodS AND MATERIALS}

The study was realized by using the three dimensional finite element techniques, for achieving the optimum conditions in lateral incisor position. In this paper, implant systems studied comprised two types of Nobel (Nobel Biocare Management AG Switzerland), one type of Neo CMI Implant (NeoBiotech, Seoul, Korea), a kind of Implantium system (Implantium, Dentium, UK Ltd.) and a Biodenta Endosteal implant (Biodenta Swiss AG, Berneck, Switzerland). DIO implant system (DIO, Haeundae-gu, Korea) also is being used with two types of DIO-ProTem Series that consisted of mini-implants series.

The 26 different implant designs of these 7 implants categories, used in this study cover the diameter range from 2 to $3.5 \mathrm{~mm}$ that these series of diameters called Narrow Platform series and some other with diameters smaller than 3 are called mini-implants. On the other wise, among these different implants, length range varies from 8 to $16.0 \mathrm{~mm}$ for upper/lower lateral incisor situation. Mandible section geometries in lateral incisor tooth position are $88.461 \mathrm{~mm}$ height, $48.514 \mathrm{~mm}$ width, and $10 \mathrm{~mm}$ thickness. In this position, the geometries of maxilla are $99.258 \mathrm{~mm}$ height, $60.495 \mathrm{~mm}$ width, and $10 \mathrm{~mm}$ thickness. Mandible and maxilla are involved cortical and cancellous. The cortical bone is outer layer of jaw. According to CBCT scans reports the thickness of this layer varies among the jaw bone that in lateral incisor teeth position, the most thickness in mandible is $22.39 \mathrm{~mm}$ and the less is $4.36 \mathrm{~mm}$. In this condition for maxilla the most thickness of cortical is $9.25 \mathrm{~mm}$ and the less is $1.085 \mathrm{~mm}$. Nevertheless, the average thickness of this layer in maxilla and mandible respectively is $7.02 \mathrm{~mm}$ and $10.31 \mathrm{~mm}$.

After modeling implant-abutment complex and bone, we apply different kinds of loads. To simulate the average masticator force in a natural loading on the implant, forces of 17.1 N, 114.6 N, and 23.4 N were applied respectively in lingual, axial, and mesiodistal directions [26]. In general, torque was generated by using two equal forces in magnitude, opposite in direction, applied to two opposite points on the diameter of the implant head. Therefore, in this paper, due to masticator forces and loads that caused by foods moving and also bruxism and clenching para-functional habits, we assume four components of torque that applied in teeth and implants. Values of torques components [27] are:

TABLE I: TORQUES IN DIFFERENT DIRECTIONS

TABLE I: TORQUES IN DIFFERENT DIRECTIONS
\begin{tabular}{|l|l|l|l|}
\hline \multicolumn{1}{|c|}{ Direction } & \multicolumn{1}{c|}{ Min Value } & \multicolumn{1}{c|}{ Ave Value } & \multicolumn{1}{c|}{ Max Value } \\
\hline Axial & 50 N.cm & - & 100 N.cm \\
\hline Lingual & 100 N.cm & - & 200 N.cm \\
\hline Distal & 100 N.cm & 200 N.cm & 300 N.cm \\
\hline $\begin{array}{l}\text { Occulasal } \\
\text { (Cronal) }\end{array}$ & 200 N.cm & 400 N.cm & 600 N.cm \\
\hline
\end{tabular}

These loads were applied on the top middle node of each implant-abutment assembly in the studied models but in different directions. These estimations about forces and torques were based on the assumption that an individual has three episodes of chewing per day, each $15 \mathrm{~min}$ in duration at a chewing rate of 60 cycles per minute $(1 \mathrm{~Hz})$. This is equivalent to 2700 chewing cycles per day. Due to the foods and liquids a thermal load is being applied to teeth and implants that it's range is between $60 \mathrm{C}$ as hot temperature and $15 \mathrm{C}$ as cold temperature [20]. Another thermal load that is applied to teeth and implants caused by drilling process. In this period must be careful that the bone temperature cannot 
exceed to $47 \mathrm{C}$ because upper temperature of $47 \mathrm{C}$ endamage to the living bone tissue. The pre-load that every time is imposed to jaw bone is caused by human skull that it's approximate weight is $16 \mathrm{~N}$. In addition, the swallowing pressure is applied to implants and teeth in cyclic form that values are:

TABLE II: SWALLOWING PRESSURE CYCLIC LOADS

\begin{tabular}{|l|l|l|l|}
\hline & Each swallowing & Per hour & Total Pres \\
\hline 16 hr-awaking & 5 Pascal & 25 time & $2000 \mathrm{~Pa}$ \\
\cline { 3 - 4 } $8 \mathrm{hr}$-sleeping & & 10 time & $400 \mathrm{~Pa}$ \\
\hline
\end{tabular}

Other kinds of loads are relative to implants preparation and installation processes that involve drilling and tightening loads. These loads are being defined according to different implants systems surgical catalogs.

Following the modeling and loading, working steps in post processing consist of: 1) Analysis 2) Interpretation of results both numerically and by color-coding. In this paper, a nonlinear and complex static, dynamic, thermal and fatigue analysis was performed. The implant-abutment configurations were analyzed by using the Finite Element Method. After FE analysis, stress distribution in the FE model comes in numerical values and in color-coding.

Material property as an effective parameter in FEA, greatly influences the stress and strain distribution in a structure. In this research, we assume that materials are linear elastic isotropic for Titanium alloys and isotropic for Cobult-Chrome alloys. The implant, abutment, and abutment screw were all designed to be Titanium, Titanium-Aluminum-Vanadium (Ti-6Al-4V) and/or cobalt-chrome alloy that are changed among the different implant systems. The Segregated properties of different components are illustrated in Table III.

TABLE III: MATERIAL OF DIFFERENT COMPONENTS OF IMPLANTS SYSTEMS

\begin{tabular}{|c|c|c|c|c|c|}
\hline & CMI & Implantium & Biodenta & Nobel & DIO \\
\hline Fixture & $\mathrm{Ti}$ & Ti-6A1-4V & Ti Gr.4 & Ti Gr.4 & Ti-C \\
\hline Abutment & $\mathrm{Ti}$ & Ti-6A1-4V & Ti-6A1-4V & Ti Gr.4 & Ti-C \\
\hline Screw & $\mathrm{Ti}$ & $\mathrm{Ti}$ & Ti-6A1-4V & Ti Gr.4 & - \\
\hline
\end{tabular}

For bone because of the porous structure, we used nonlinear isotropic properties. Two types of bone density were modeled by varying the elastic modulus of compact bone and cancellous bone (with high and low densities) to account for the effect of the bone behavior on the implant accurately. The fragmental mechanical properties of materials that been used in this study are listed in Table IV.

After material properties were applied, a mesh 3D finite element model was constructed. The element in meshing all three-dimensional models is eight nodes Brick element (SOLID45), which has three degrees of freedom (translations in the global directions).

The interface between implant and bone was modeled as an immovable and rigidly junction, which simulated the condition of the optimal implant osseointegration. For this purpose, "Fixed Geometry" option in the software was chosen. The bone and implants simulated models, which were meshed tetrahedron elements. Another relevant parameter in meshing is mesh density. In this paper, a finer mesh was generated around the implant.

Next in our research, we peruse different implants of five implants systems that are chosen. Osseointegration of bone and influence of it success of the implantation is the most important factor. Any failure in osseointegration process can cause rejection of implant by bone and therefor complete failure of implantation process. However, some factors such as position of implant installation, bone quality, and angle of implantation are affected in osseointegration. Therefore, in this study we investigate implants with different properties in lateral incisor position and with different angulation of implantation and different cases of angle abutment.

TABLE IV: MECHANICAL PROPERTIES OF IMPLANTS AND BONE

\begin{tabular}{|c|c|c|c|c|c|}
\hline \multirow{2}{*}{ Material } & $\begin{array}{c}\text { Elastic } \\
\text { Modulus }\end{array}$ & $\begin{array}{c}\text { Shear } \\
\text { Modulus }\end{array}$ & $\begin{array}{c}\text { Tensile } \\
\text { Strength }\end{array}$ & Density & $\begin{array}{c}\text { Poisso } \\
\text { n Ratio }\end{array}$ \\
\cline { 2 - 6 } & \multicolumn{5}{|c|}{$(\mathrm{MPa})$} \\
\hline Ti Gr.4 & 105000 & 45000 & 550 & 4510 & 0.37 \\
\hline Ti6A14V & 105800 & 41023 & 827.37 & 4428.78 & 0.31 \\
\hline $\mathrm{Ti}$ & 105000 & 45000 & 440 & 4500 & 0.37 \\
\hline Co-Cr & 190000 & & 1200 & 8290 & 0.3 \\
\hline Cortical & 14000 & & 7.82 & 1720 & 0.3 \\
\hline Cancellous & 1370 & & & & 0.3 \\
& & & & & \\
\hline
\end{tabular}

In order to angle abutments of different implants systems, considered five classifications that adequate to these classifications we put implants in bone models. In below table, shows the classification in terms of implants:

In this study, after analyzing implants, we interpret of results both numerically and by color-coding to achieve the best case for lateral incisor position in terms of angles.

TABLE V: ANGLE OF ABUTMENTS AND IMPLANTATION IN TERMS OF IMPLANTS SYSTEMS

\begin{tabular}{|c|c|c|c|c|c|}
\hline $\begin{array}{c}\text { Angle of } \\
\text { Abutment }\end{array}$ & 15 & 17 & 20 & 25 & 30 \\
\hline Biodenta & a & & - & & \\
\hline $\mathrm{CMI}$ & a & & & a & \\
\hline IMPLANTIUM & " & & & " & \\
\hline Nobel & & ! & & & ! \\
\hline
\end{tabular}

\section{RESULTS AND DISCUSSIONS}

Primary implant stability and bone density are variables, which are considered essential to achieve predictable osseointegration and long-term clinical survival of implants. According to position of lateral incisor that has it been placed between central incisor and canine; therefore has lake of space to replacing the implants. In addition, in some cases because of accident or congenital problems, jaws are being unformed. In such situations, angled abutments seem to have an upper hand over the straight abutments as they permit the implant placement in an ideal location in the bone without compromising the esthetics. Hence, permitting a greater number of patients to be treated with implant therapy. In the case of lateral incisor teeth, usually using angulated implantation and angled abutments reduces the problem. This will be provided primary stability of implant and achieve the optimum osseointegration. In general, angled abutments facilitate restoration of implants placed with bucco-lingual or mesiodistal misalignment. Numerous types of prefabricated abutments are available at specific angles. Angled abutments with angulations varying from $15^{\circ}$ to $35^{\circ}$ often are commercially available. A $15^{\circ}$ angulation of a prefabricated abutment can create parallelism between adjacent abutments. 
Additionally, correcting an implant trajectory with a $15^{\circ}$ angled abutment can shift a restoration approximately 1.0 to 1.5 millimeters at the occlusal aspect, and a $25^{\circ}$ abutment can move it from 2.0 to $2.5 \mathrm{~mm}$ [28]. Other types of angular abutments with a certain angles can shift other aspects.

In the present study, a 3D FEA was performed to analyze the stress distribution within four different bone types (i.e Lekholm and Zarb classification) due to loads applied to different implant systems. The minimum bone stress was produced with straight abutment and vertical force whereas the maximum bone stress was obtained with $15^{\circ}$ angulated abutment and coupled forces. In addition, the lower is the bone quality (i.e. D4), the higher is the distribution of the stress within the bone.

In our study, by exposing 26 different implants with their proportional abutments, and screws under following loads gradually and then finite element analyses, stress distribution in the FE model comes in numerical values and in color-coding. By several criteria can interpret the results of numerical and color-coding that one of these criteria is being Von Misses criteria. According the Von Misses criteria and in terms of different angles that considered angle implantation for lateral incisor position in mandible and maxilla and consequently used proportional angled abutments. In this study we investigate, stress distributions according to Von Misses criteria for some different categories. These categories are in terms of different implants systems and various angles that presented in Fig. 1.

In this study, it investigated effect of angles in implants success under complex loads on implants that includes static, dynamic, thermal and fatigue loads. The results obtained with the FEA simulation showed the relationship between loads applied on the system, geometrical characteristics of materials, joints, and strain. Some the FEA simulation results are presented in Fig. 2.

Except experimental articles that due to having enough time to passionately convey the planting process according to the physician faced with a variety of jaw bone of the patient and the physician in selecting the types of implants, in most conditions, theoretical papers have some restrictions that this issue cause to obtain various assumptions during FEA in various studies with quite different results. We tried to resolve these discrepancies. Therefore, we have some innovations in this article. At first, it is noteworthy that checking out of lateral incisor issue of dental implants has been lacking so far in the debates. Our other innovations are:

1) Evaluation of the theoretical results is conformity with clinical studies.

2) Neglecting hundred percent osseointegration and imposed the micro-gap.

3) In most previous papers, just have been considered occlusal force, but in fact, other various loads are being effected on the implant that in this paper have been considered.

4) Because of the geometry complexities of the jaw in some papers, is not being chosen the suitable elements for analysis, nevertheless, in this paper, the number of elements and nodes is selected according to the optimum results.

and some others.

\section{CONCLUSIONS}

Based on the available data in this study, we can draw several conclusions:

1) In general, angled abutments increased stress levels on the implants and adjacent bone, but it does not mean that with using angle abutment must be occurred failure sooner. Nevertheless, in some positions such as anterior lateral using angle abutments might be useful. In general, among the all models, almost three situations have more critical condition than others do. These situations are variables in different situations and angles that at certain angles and positions, one, two, or three situations are critical. The most critical situation is related to connecting implant and abutment section. Other critical sections are abutment surface and top of the abutment.

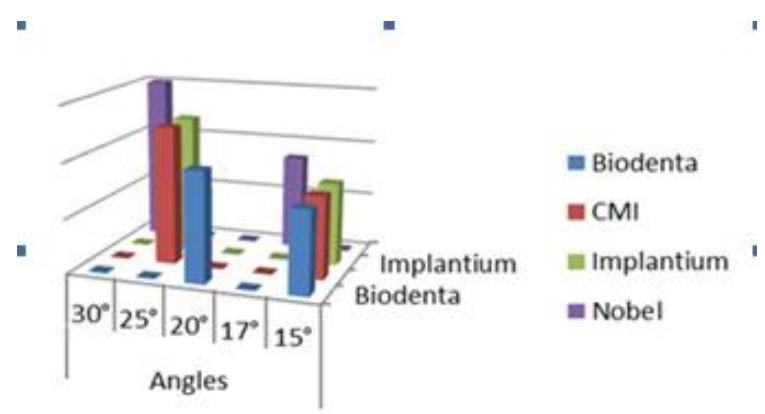

Fig. 1. Different implants with angles categories.

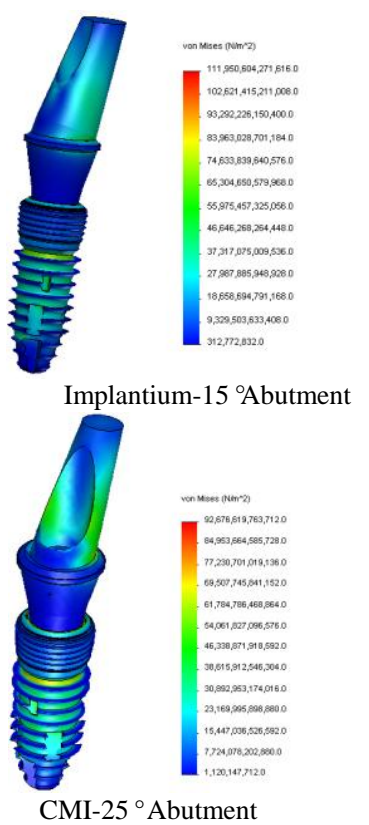

Fig. 2. FEA simulation result.

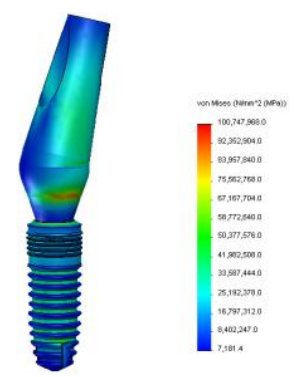

CMI-15 Abutment

2) Use of angled abutment in range 20-25 degree can decrease stress in comparison of lower than 20 degree and upper than 30 degree.

3) By increasing the angle from 15 to 25 maximum von misses stress is being decreased.

4) In used of angled abutments, neck section of the implants is subjected to maximum loads and stress.

5) With increasing the angle from 25 to 30 maximum von misses stress is being increased.

\section{ACKNOWLEDGMENT}

The authors wishes to express their deepest gratitude to Dr 
H.Mehdizade, Decedent Dr. H. Hamidi, Mr. D. Porafshar, Dr. Zeratiyan, Eng. Kazempour, Eng. Asakere, , Eng. Fathi and some others for their great helps and efforts.

\section{REFERENCES}

[1] S. E. Eckert and P. C. Wollan, "Retrospective review of 1170 endosseous implants placed in partially edentulous jaws," Journal of Prosthetic Dentistry, vol. 79, no. 4, pp. 415-421, 1998.

[2] A. M. Roos-Jansåker, C. Lindahl et al., "Nine to fourteen-year follow-up of implant treatment. Part I: implant loss and associations to various factors," J. Clin. Periodontol, vol. 33, pp. 283-289, 2006.

[3] E. Romeo et al., "Long-term clinical effectiveness of oral implants in the treatment of partial edentulism. Seven-year life table analysis of a prospective study with ITI dental implants system used for single-tooth restoration," Clin. Oral Implants, Res, vol. 13, pp. 133-43, 2002.

[4] C. A. Simmons, S. A. Meguid, and R. M. Pilliar, "Differences in osseointegration rate due to implant surface geometry can be explained by local tissue strains," Journal of Orthopaedic Research, vol. 19, no. 2 , pp. 187-194, ISSN 1554-527X, March 2001.

[5] J. C. De V. R. Dealyed, "Loading in implantology," Rev. Esp. Cir. Oral y. Maxilofac, vol. 27, pp. 271-286, 2005.

[6] R. Gapski, H. L. Wanh, P. Mascarenhas, and N. P. Lang, "Critical review of immediate implant loading," Clin. Oral Implants Res., vol. 14 , pp. 515-527, 2003.

[7] T. D. Taylor, U. Belser, and R. Mericske-Stern, "Prosthodontic considerations," Clinical Oral Implants Research, vol. 11, pp. 101-107, 2000.

[8] V. O. Kokich Jr. and G. A. Kinzer "Managing congenitally missing lateral incisors. Part I: Canine substitution," J. Esthet. Restor. Dent., vol. 17, no. 1, pp. 5-10, 2005.

[9] V. G. Kokich, "Maxillary lateral incisor implants: planning with the aid of orthodontics," J. Oral Maxillofac Surg., vol. 62, no. 9, Suppl 2, pp. 48-56, 2004.

[10] G. Richardson and K. A. Russell, "Congenitally missing maxillary lateral incisors and orthodontic treatment considerations for the single-tooth implant," J. Can. Dent. Assoc., vol. 67, no. 1, pp. 25-8, 2001.

[11] D. Buser, U. Belser, and D. Wismeijer, ITI Treatment Guide: Implant Therapy in the Esthetic Zone for Single-Tooth Replacements, 1st ed., Quintessence, Berlin, 2007.

[12] S. Winkler et al., "Implant replacement of congenitally missing lateral incisors: A case report," J. Oral Implantol, vol. 34, no. 2, pp. 115-18, 2008.

[13] F. Zarone, R. Sorrentino, F. Vaccaro, and S. Russo, "Prosthetic treatment of maxillary lateral incisor agenesis with osseointegrated implants: A 24-39-month prospective clinical study," Clin. Oral Implants Res, vol. 17, no. 1, pp. 94-101, 2006.

[14] S. Kourtis et al., "Provisional restorations for optimizing esthetics in anterior maxillary implants: a case report," J. Esthet. Restor. Dent., vol. 19, no. 1, pp. 6-17, 2007.

[15] S. D. Brown and A. G. Payne, "Immediately restored single implants in the aesthetic zone of the maxilla using a novel design: 1-year report," Clin. Oral Implants Res., vol. 22, pp. 445-54, 2011.

[16] A. Sethi et al., "Evolution of the concept of angulated abutments in implant dentistry: 14-year clinical data," Implant Dent., vol. 11, pp. $41-51,2002$

[17] G. Dubois et al., "Biomechanical study of a prosthetic solution based on an angled abutment: Case of upper later incisor," Med. Eng. Phys., vol. 29, pp. 989-98, November 2007.

[18] D. E. Eger, J. C. Gunsolley, and S. Feldman, "Comparison of angled and standard abutments and their effect on clinical outcomes: A preliminary report," Int. J. Oral Maxillofac Implants., vol. 15, no. 6, pp. pp. 819-823, 2000.

[19] A. Sethi, T. Kaus, and P. Sochor, "The use of angulated abutments in implant dentistry: Five-year clinical results of an ongoing prospective study," Int. J. Oral Maxillofac Implants., vol. 15, no. 6, pp. 801-810, 2000.

[20] A. Sethi et al., "Evolution of the concept of angulated abutments in implant dentistry: 14-year clinical data," Implant Dent., vol. 11, no. 1, pp. 41-51, 2002.

[21] P. Maló, N. A. Mde, U. Petersson, and S. Wigren "A pilot study of complete edentulous rehabilitation with immediate function using a new implant design: case series," Clin. Implant Dent Relat Res., vol. 8, no. 4, pp. 223-232, 2006.
[22] A. Rosén and G. Gynther, "Implant treatment without bone grafting in edentulous severely resorbed maxillas: A long-term follow-up study," $J$. Oral Maxillofac Surg., vol. 65, no. 5, pp. 1010-1016, 2007.

[23] R. Calandriello and M. Tomatis, "Simplified treatment of the atrophic posterior maxilla via immediate/early function and tilted implants: A prospective 1-year clinical study," Clin. Implant Dent. Relat. Res., vol. 7, Suppl 1, pp. S1-S12, 2005.

[24] G. Krennmair et al., "Clinical outcome and prosthodontic compensation of tilted interforaminal implants for mandibular overdentures," Int. J. Oral Maxillofac Implants, vol. 20, no. 6, pp. 923-929, 2005.

[25] C. Aparicio, P. Perales, and B. Rangert, "Tilted implants as an alternative to maxillary sinus grafting: a clinical, radiologic, and periotest study," Clin. Implant Dent. Relat. Res., vol. 3, no. 1, pp. 39-49, 2001.

[26] O. Kayabasi et al., "Static, dynamic and fatigue behaviors of dental implant using finite element method," Advances in Engineering Software 37, pp. 649-658, 2006.

[27] E. C. Misch, Contemporary Implant Dentistry, $3^{\text {rd }}$ ed., Mosby, Missouri, US, 2007.

[28] J. Cavallaro and G. Greenstein, "Prosthodontic complications related to implant placement," in S. J. Forum ed., Dental Implant Complications: Etiology, Prevention, and Treatment. Chichester, West Sussex, England: Wiley-Blackwell, pp. 156-171, 2010.

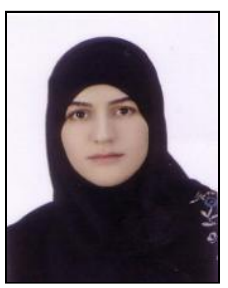

Z. Arsalanloo was born in Urmia of West Azerbayjan in 1988, and now she lives in Urmia. She studied agricultural machinery in Urmia University from 2007 to 2011. She earned her B.A degree in agricultural machinery engineering (biotechnology engineering). She is a MSc student of mechanical engineering (applied design) in the Faculty of Engineering, Vali-e-Asr University of Rafsanjan, Iran. She is working on dental implants. She has various papers that were accepted in several conferences and journals, such as ISME2013, ISBME, SJME, others. She also works in heat treatment and finite element analysis. Hence, she has a subscribed book with R. Telchi in Title "Weld molds heat treatment". Another book that she and R. Telchi are written is under the publishing with implants issue.

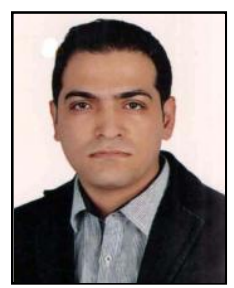

R. Telchi was born in Urmia of West Azerbayjan in 1988, and now he lives in Urmia. He studied agricultural machinery in Urmia University from 2005 to 2009. He earn his B.A. degree in agricultural machinery engineering (biotechnology engineering). $\mathrm{He}$ is a M.Sc. student of mechanical engineering (applied design) at School of Engineering and Science, Sharif University of Technology, International campus, Kish, Iran. He is working on dental implants. He has various papers that were accepted in several conferences and journals, such as ISME2013, ISBME, SJME, others. He also works in heat treatment and finite element analysis. Hence he has a subscribed book with Z. Arsalanloo in title "Weld molds heat treatment". Another book that he and Z. Arsalanloo are written is under the publishing with implants issue.

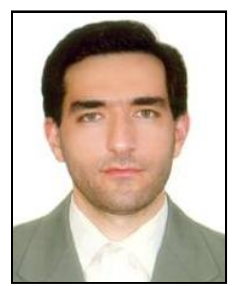

K. G. Osgouie was born in Isfahan in 1977, and now he lives in Kish Island. He earned his B.A., M.Sc. and $\mathrm{PhD}$ degrees in mechanical engineering from Sharif University of Technology, Tehran, Iran.

$\mathrm{He}$ is the head of Mechatronics and Applied Design Groups, School of Engineering and Science, Sharif University of Technology International Campus, Kish Island, Iran, since 2009. He is as a assistant professor of Mechatronics and Applied Design Mechanical Engineering. He is working on various topics that recently he works on dental implants too. He has various papers that accepted in various conferences and journals. He also works Robotics, Artificial Intelligence (Genetic Algorithms, Neural Networks, etc), Advanced Control, Vibrations of Continuous Systems, Optimal Design in Mechanical Engineering, Mechatronics, and Composite Materials.

Dr. Osgouie is ASME, IEEE member. He is a reviewer of ASME/IEEE (USA), Robotica (Cambridge University Press, England), Scientia Iranica (Elsevier Science BV, Iran). He ranked 102nd out of 210,000 students allover Iran in the National University Entrance Examination, 1995 and 21st out of over 3500 students allover Iran in the National Examination for Entrance in Post Graduate Studies (M.Sc.), 1999. 